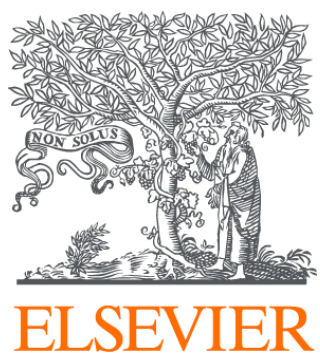

Since January 2020 Elsevier has created a COVID-19 resource centre with free information in English and Mandarin on the novel coronavirus COVID-

19. The COVID-19 resource centre is hosted on Elsevier Connect, the company's public news and information website.

Elsevier hereby grants permission to make all its COVID-19-related research that is available on the COVID-19 resource centre - including this research content - immediately available in PubMed Central and other publicly funded repositories, such as the WHO COVID database with rights for unrestricted research re-use and analyses in any form or by any means with acknowledgement of the original source. These permissions are granted for free by Elsevier for as long as the COVID-19 resource centre remains active. 


\title{
Benefits, barriers, and incentives for improved resilience to disruption in university teaching
}

\author{
Jacqueline Dohaney $^{\mathrm{a}, \mathrm{c}, *}$, Mairéad de Róiste ${ }^{\mathrm{b}}$, Rhian A. Salmon ${ }^{\mathrm{c}}$, Kathryn Sutherland ${ }^{\mathrm{d}}$ \\ ${ }^{a}$ STEM Practice \& Innovation Academy, Swinburne University of Technology, Australia \\ ${ }^{\mathrm{b}}$ School of Geography, Environment, and Earth Sciences, Victoria University of Wellington, New Zealand \\ ${ }^{\mathrm{c}}$ Centre for Science in Society, Victoria University of Wellington, New Zealand \\ ${ }^{\mathrm{d}}$ Centre for Academic Development, Victoria University of Wellington, New Zealand
}

\section{A R T I C L E I N F O}

\section{Keywords:}

Resilience

Disruption

Academic continuity

Business continuity

Academic development

\begin{abstract}
A B S T R A C T
Pandemics, earthquakes, fire, war, and other disasters place universities at risk. Disasters can disrupt learning and teaching (L\&T) for weeks to months or longer. Some institutions have developed business continuity plans to protect key organisational services and structures, allowing L\&T to continue. However, little research touches on how academics, learners, and communities of practice might respond before, during, and after disasters and how their resilience to disruption can be fostered to reduce impacts on L\&T.

In this research, we investigated academics' perceptions of building resilience to major L\&T disruptions in the New Zealand context. Specifically, we explored how academics characterise a resilient academic and institution, and identified the benefits, barriers, and incentives to building resilience. We used a pragmatic theoretical approach with a mixed methods methodology, to categorise the results within three distinct levels (individual, school/department, and institution), supporting the design and implementation of resilience-building strategies for academics and institutional leaders.

We found that support, community, leadership, and planning at universities are critical in building and inhibiting resilience. Participants reported several 'high impact' incentives, addressing multiple barriers, that could be used to kick-start resilience. Online and flexible learning are key opportunities for resilience-building, but universities should not underestimate the importance of face-to-face interactions between staff and learners. Our results provide a strong starting point for practitioners and researchers aiming to understand how universities can foster resilience to major disruptions and disasters on university teaching.
\end{abstract}

\section{Introduction}

Earthquakes, fire, war, pandemics, and other disasters place universities at risk. Disasters can disrupt learning and teaching (L\&T) for weeks to months, and even longer. Such significant disruptions are likely to multiply with increasing urbanisation, over-population and changing climate influences like extreme weather events [1]. Discontinuing L\&T, even in the short-term, can lead to "substantial financial loss, reputation damage, job losses, \{and\} curriculum limitations" [2] requiring universities to be resilient and agile in the face of adversity.

Universities have adopted business continuity plans (e.g., for extreme weather in the United States [3,4], similar to other organisations (e.g. Ref. [5]), either in anticipation of or in response to disasters. These plans aim to support the university's ability to manage disruption and provide L\&T after crisis events. These solutions are typically institution-scale and focus on the management of disrupted services, grounded in organisational resilience approaches (e.g., Ref. [6]).

Resilience is a well-known concept but bears multiple meanings and is often conflated with risk. Risk is the exposure to a disaster while resilience is the recovery from that event [5]. However, resilience is defined differently according to its social context and disciplinary approach (as described in Ref. [5]). For example, psychology defines resilience as how individuals respond to a challenging event (e.g. Ref. [7]), while education extends to learners' ability to cope and thrive through adversity (e.g., Ref. [8] a.k.a., educational resilience [9]). In the education literature alone, resilience can be considered as "a state, a condition and a practice" ([10]; pg. 543).

Resilience to disruption can also be known as institutional [11],

\footnotetext{
* Corresponding author. Lecturer in STEM Education, Swinburne University of Technology, John St, Hawthorn, Victoria, 3122, Australia.

E-mail addresses: jdohaney@swin.edu.au (J. Dohaney), mairead.deroiste@vuw.ac.nz (M. de Róiste).
} 
instructional, or academic continuity [12,13]. Academic continuity is the capability of institutions and academics to continue delivering L\&T following a disruptive event. Academic continuity strategies have been documented by tertiary institutions responding to extreme weather and health crises, in particular, the H1N1 flu pandemic in 2009 [14].

Indeed, the differing conceptual approaches embraced by individuals and institutions can determine the framework implemented which will in turn influence their chosen actions and priorities [5]. For example, academic continuity has often focused, almost exclusively, on the use of digital technology to provide L\&T during the event. Ensuring a common understanding of resilience is, therefore, important in exploring its conceptualisation and possible manifestations within higher education institutions.

As institutional scale resilience, or business continuity, has been a focus in the literature, the effects of L\&T disruption on individual teaching practice has received little attention. This focus on the organisation is not unique to the academic sector and resilience is often explored at societal, community, or organisational scales [5]. In universities and other tertiary institutions, academics are responsible for how courses are delivered, materials presented, and what content is included. Additionally, current institutional approaches tend to be responsive, rather than preventive, and focus predominantly on reducing the institutional economic risk following an event (e.g., wide scale online provision in the wake of COVID-19 when face-to-face tuition was impossible). Understanding the role of resilience in higher education and the difficulties faced by academics in making their practice resilient facilitates ongoing resilience rather than responses to singular events.

This article explores academic and organisational resilience in university teaching, specifically academics' perceptions of the benefits, barriers, and incentives to building resilience. Our investigation is supported by two key research questions: 1) How do university staff describe a resilient academic and a resilient institution? and 2) What do university staff describe as the benefits, barriers, and incentives to building resilience? We explore both institutional and academic continuity but look further into individual perceptions of resilience-building in the university context.

\section{Methodology}

We applied a mixed methods methodology grounded in a postpositivist pragmatic approach (e.g. Ref. [15]), using interviews, focus groups, and questionnaires. The key aim of the research was to identify key problems when L\&T is disrupted and provide solutions leading to improved resilience. Approval for this research was granted by Victoria University of Wellington (VUW) human ethics committee (\#22950). In this section, we first describe the context in which this research was undertaken, followed by the participants involved, and the methods for data collection and analysis employed.

\subsection{Study site}

VUW is distributed across three campuses within Wellington in New Zealand and several smaller locations across the region. It is situated within an active earthquake zone and is at risk from several natural disasters [16], but, until 2010/11, the potential impact to university L\&T at VUW had not been well explored.

In 2010 and 2011, the Canterbury earthquake sequence occurred causing fatalities, significant damage to the built and natural environment, and disruption of social and economic activities across the Canterbury region in New Zealand [17]. The scale of the disruption on the local university (the University of Canterbury) [18], and other earthquake events in New Zealand, increased the awareness of potential impacts to VUW. In response, the Pro-Vice-Chancellor of Sciences, Engineering, Architecture and Design (SEAD) established a resilience Steering Group (i.e., a community of practice and research project) to explore how we can prepare staff and learners and promote L\&T continuity in the event of significant disruption. The group ran from July 2014 to August 2017 and explored issues, such as post-disruption access to infrastructure and services, communication, staff and student support, and existing resilience and contingency plans. Here, we present our investigation into how the Steering Group, and other university staff, perceived resilience to disruption and its improvement. The most likely scenario envisaged was an earthquake but other possible disasters were also considered, including pandemics.

\subsection{Participants}

Our participants were sampled from two groups of people. First, was the resilience Steering Group (SG) consisting of 8 academics across the SEAD faculties (including the second and third authors of this paper), 6 professional central-service unit staff, and a resilience coordinator (including the first author of this paper). The SG were asked to participate in the research via email, and ten took part ( 5 academics, and 5 professional staff). The second group of participants were SEAD academics, not members of the Steering Group (NSG) $(n=8)$. The purpose of engaging this second group was to: 1) assess perceptions of those who had not been immersed in the topic, 2) raise awareness of resilience to disruption across SEAD, 3) share ways to build resilience, and 4) gauge their initial level of 'buy-in' while being new to the initiative. We aimed to sample across the disciplines, length of teaching experience, and workloads. NSG were recruited via an institutional e-newsletter and L\&T community e-mailing list. To meet our cross-discipline sample, three participants were recruited directly by email.

All participants $(n=18)$ were asked to complete a hardcopy questionnaire at the start of the interview. Questions included: gender, age, nationality, ethnicity, discipline, teaching and research workload, and teaching experience. Participants included equal numbers of women (9) and men (9), a wide range of origin nationalities (11 from NZ and 7 overseas), and a broad age-spread (30-65, median of 44). The ethnicity of the participants was predominantly European New Zealander or European with one Māori participant.

All participants were permanent (i.e., ongoing) staff (13 academic, 3 professional, and 2 teaching-only roles) across a wide range of academic disciplines: architecture and design (1), atmospheric science (1), geography (1), biology (2), science history (1), chemistry (2), software engineering (1), statistics (1), mathematics (2), and psychology (2), educational technology (3), and fine arts (1). Participants also reported a range of teaching experience (0-33 years, median of 11), mostly teaching-heavy course loads (15), with a range of 2-7 courses per year and all but one of these 15 participants co-teach at least one course. Overall, participants reported diverse workload proportions with teaching-dominant (6), service-dominant (5), or distributed evenly amongst research/teaching/service (7).

\subsection{Interviews}

We interviewed participants in one-on-one and focus group formats (lasting 40-120 min). SG participants were interviewed first (2 focus groups, and 4 one-on-ones), followed by NSG participants ( 1 focus group, 5 one-on-ones). The resilience coordinator (Dohaney) led the interviews with the participants and was known to the SG but not known to the NSG, and had personally experienced long-term L\&T disruption during the Canterbury earthquakes.

The semi-structured interview protocol (see supplementary material) focused on (Part 1) characterisations of resilience to disruption, and (Part 2) benefits, barriers, and incentives to building resilience. Part 1 was used as a meaning-making experience for the SG, allowing us to form characterisations of resilience to disruption for communication with the wider community. Part 2 aimed to characterise the benefits, barriers, and incentives of resilience-building. Part 1 results were coded, summarised, and shared with NSG participants to introduce the 
resilience initiative and help them understand the context of the project, before proceeding to Part 2 . During the interviews, we asked interviewees to take several moments to themselves to read and think about the questions and then write down (hardcopy) their thoughts before discussing them. These participant notes (including the same question prompts) were considered primary data and collected when the interview was completed. Participant notes were collected to triangulate the verbal data and capture individual views (within the focus group format). Interviews and participant notes were de-identified and transcribed by an external research assistant prior to data analysis.

\subsection{Data analysis}

We initially approached the datasets holistically and then interrogated the data at different levels (micro, meso, and macro). The first author completed the data analysis (using ATLAS.ti qualitative coding software) using a conventional approach to content analysis ([19]; pg. 475-476). Using a pragmatic approach, we documented a wide range of unique perceptions prioritising breadth and comprehensiveness over depth of description.

The participant's notes were analysed first as they represent individual views and because participants often wrote responses in bulleted lists, which helped to create quick, first-impressions of the data. Next, the interview data was coded, and initial codes assigned. The codes were then interrogated, and clusters of similar codes were viewed as a Network view (i.e., a visual display of all codes and quotations). This overview allowed the researcher to compare all codes, check their frequency of mention, cull redundancies, merge similar-meaning codes, and group codes into categories. Careful consideration was taken to avoid duplication of themes noted by individual participants. Triangulation of key themes and codes was made possible by checking interview dialogue with and against individual participant notes.

Four themes (characterisations, benefits, barriers, and incentives) served as a priori code categories for thematic analysis, developed during the interview protocol. Sub-categories developed and were differentiated at the micro-level (i.e., individuals), meso-level (i.e., schools or departments), and macro-level (i.e., institution) within the New Zealand context, supported by a multilevel theory approach [20,21]. Using a multilevel theory approach allows researchers to investigate phenomena within and between major levels (or scales) of a system. This approach appealed to the researchers, as we intended to operationalise our findings into resilience-building initiatives within the existing levels of the university socio-political-system. We, therefore, organised and presented the themes by level. This approach does not follow a systems analysis (i.e., identifying vulnerabilities within a system) but retains the focus on academics' perspectives.

Once a coding scheme was developed, the second and third authors checked the codes to support code generation, clustering, and scheme refinement, while the fourth author (who had no prior involvement in the data analysis) checked the final code scheme through independently coding a full transcript (randomly-chosen participant), resulting in minor additions to one code category and rewording/clarification of another. Code frequencies were used to guide our aggregation, clustering or parsing of information. Several codes had low frequencies but clustering data in these areas reduced comprehensiveness of a resilience planning/building solution thereby reducing its utility (i.e., supported by our pragmatic approach) to building a solution for increased resilience. Code categories and sub-categories were checked for statistical relationships between subpopulations (i.e., did participants with more teaching experience report more learner-centred benefits to resilience?) but no significant relationships were found; consequently, the findings are not presented by subpopulation.

\section{Results and discussion}

The results and discussion are presented within the four major themes identified in our data analysis: our community of practice's characterisation of resilience to disruption, followed by the benefits, barriers, and incentives to building resilience. The following sections of the paper are intended to assist the thinking and planning of university academics, staff, and leaders as they consider their own local context. Our tables (Tables 1-3), in particular, offer individual academics, schools, and academic institutions many factors which influence resilience to disruption. Longer excerpts of text supporting Tables 1-3 are available in the online supplementary material.

\subsection{How academics characterise resilience to disruption}

Here, we present the SG's characterisation of academics and higher education institutions resilient to disruption, within our institutional and cultural context. Both characterisations were developed as shared ideals rather than rigid standards, or definitions, and should reduce L\&T disruption regardless of the severity of the disruption.

Resilient academics (in the order of most frequently mentioned codes):

- are flexible, adaptable, emotionally-resilient, collaborative, empathetic, open-minded individuals (attributes);

- respond quickly during a disruption, are digitally literate, organised, prepared and creative-thinkers (capabilities);

- have a sound awareness of their courses, learner-centred approaches, L\&T delivery options during disruptions, emergency protocols, and the wider institutional system (knowledge).

Resilient institutions have the following characteristics (in the order of most frequently mentioned codes):

- effective communication channels,

- a coherent crisis communication strategy,

- an established, coherent, L\&T disruption plan across all levels of the institution,

- strong resilience-building leadership,

- existing emergency response plans and management,

- existing flexible, blended, and digital learning strategies,

- support for staff to undertake resilience-building initiatives,

- support for staff to develop digital literacy,

- effective and easy-to-use digital infrastructure,

- a strong sense of staff and learner community, and

- existing rewards/schemes to promote engagement with academic professional development (aligned to resilience qualities, above).

The characterisations contain major themes that emerged throughout the study and include (in no particular order): flexibility, communication, community, support, strategic planning, preparedness, and leadership. Both sets of characteristics highlight flexible learning pedagogies (i.e., L\&T delivered through a variety of modes, contexts and settings [22]), therefore, flexible learning research and initiatives may provide a critical remedy for building resilience to disruption. However, the characterisations also include sustainable and long-term resilience measures [4] that shift the focus away from short-term (threat-dependent) solutions, advocated by researchers in business continuity community. It is also notable that these characterisations do not rely on a risk assessment, often interwoven with more organisational scale approaches (e.g., Ref. [23].)

In Kwok et al. [24], participants described resilient communities (i. e., social resilience) to have many structural and cognitive characteristics “... [requiring] not only the necessary personnel, economic resources, and community physical assets, it also entails 'resilient' attitudes and beliefs that drive positive resolutions to disaster-related challenges." (pg. 207). The participants in our research mirrored these more community- and individual-based attitudes (e.g., open-minded) with a recognition that resourcing needs to occur at an institution scale. 
Table 1

Benefits to improving resilience.

\begin{tabular}{|c|c|}
\hline Before a disruption, (22) & During (34) and After (6) a disruption, \\
\hline \multicolumn{2}{|c|}{ Competency: Resilient academics will ... (18/18) } \\
\hline be more organised. (9) & better support their colleagues. (7) \\
\hline have their teaching organised, allowing them to focus on other things. (8) & know what to consider. (7) \\
\hline know what to expect, if there is a disruption. (7) & better support their families. (6) \\
\hline use resilience, to make them a better academic in general. (6) & get back to 'normal' more quickly. (5) \\
\hline have increased adaptiveness. (4) & achieve things and get things done. (4) \\
\hline be more responsive to a wide range of everyday disruptions. (3) & be flexible to the changing circumstances. (3) \\
\hline use resilience capabilities in a non-disruption. (2) & know what they can and can't control. (2) \\
\hline have more shared knowledge with colleagues. (2) & develop future-focussed skills and strategies. (1) \\
\hline be open to new ideas. (1) & have teaching materials 'ready to go'. (1) \\
\hline & have new outlooks on L\&T (1) \\
\hline \multicolumn{2}{|c|}{ Emotional state: Resilient academics will feel ... (16/18) } \\
\hline - more confident about their job. (1) & (relatively) in control. (8) \\
\hline more empathy for colleagues and learners. (1) & emotionally prepared. (7) \\
\hline & like they can cope. (5) \\
\hline & less stressed. (4) \\
\hline & (relatively) calm. (3) \\
\hline & less miserable. (1) \\
\hline & more confident about their job. (1) \\
\hline \multicolumn{2}{|c|}{ Resilient L\&T will $=\ldots(15 / 18)$} \\
\hline be simplified from day-to-day. (9) & be focussed on learning outcomes rather than course logistics. (9) \\
\hline be resilient to academic illnesses. (6) & be flexible to changing delivery modes. (4) \\
\hline be more innovative (i.e., academics trying new L\&T strategies). (6) & be able to continue, during the disruption. (3) \\
\hline be more incentivised towards improved L\&T. (3) & include courses that are flexible to a range of instructors. (3) \\
\hline be better understood at the school-level. (3) & be changed from current L\&T practice. (2) \\
\hline be more efficient. (2) & be more innovative. (1) \\
\hline be resilient to academic absences (e.g., sabbatical). (2) & be easier. (1) \\
\hline $\begin{array}{l}\text { have built-in, time-saving resources. (1) } \\
\text { be more digital. (1) }\end{array}$ & \\
\hline \multicolumn{2}{|c|}{ Resilient institutions will ... (13/18) } \\
\hline build time-saving digital infrastructure. (2) & be prepared for the disruption. (4) \\
\hline improve programme management at the school-level. (1) & effectively respond to the disruption. (2) \\
\hline & allow academics to show leadership. (2) \\
\hline & have an emergency plan in place. (1) \\
\hline & be less stressed. (1) \\
\hline & get back to 'normal' faster. (1) \\
\hline & have independent academics who can work without much guidance. (1) \\
\hline & have improved abilities to deal with major issues that arise. (1) \\
\hline & help by reducing stress on the wider region. (1) \\
\hline \multicolumn{2}{|c|}{ At a resilient institution, learners will ... (9/18) } \\
\hline & experience better support. (8) \\
\hline & feel less stressed. (2) \\
\hline & experience a safe and stable work environment. (2) \\
\hline & continue their studies. (1) \\
\hline & see role models in the response to disruption. (1) \\
\hline
\end{tabular}

We consider these characterisations as a starting place for understanding resilience to disruption and useful to individuals and groups seeking to improve resilience at their institution. No institution is alike, and these characterisations come from a specific university within New Zealand. Each university and individual are likely to experience different resilience dimensions to a greater or lesser extent. However, these sets of characteristics provide a firm starting point which can be provided to other higher education institutions and individuals to explore their understanding of resilience and upon which a customised plan, taking into consideration their unique vulnerabilities and areas for improvement, can be created.

\subsection{Preparing for disruption: benefits, barriers, and incentives}

Building from these characterisations of resilient academics and their institutions, we identify here the benefits our participants perceived in preparing for disruption (i.e., increasing resilience), the barriers faced when building resilience, and incentives to help overcome these barriers. While the responses are specific to our institution, we expect these dimensions to be helpful in forming a scaffold for other institutions or individuals to develop their own pathways to greater resilience. Different stages of a disaster exist whether the disaster policy cycle (mitigation, preparedness, response, and recovery [25], or the disruption cycle (plan, absorb, recover, and adapt [26]) are envisaged. Recognising these stages and acknowledging that each stage brings different challenges, we conceptualise and investigate resilience as how individuals, schools, and universities perceive both preparing for and responding to disasters.

\subsubsection{Benefits of resilience}

Increasing resilience by preparing for a major disruption has benefits in the immediate and longer-term aftermath of a disaster, for both institutions and individual academics. Table 1 shows the ways in which the participants anticipated that preparing for disruption will benefit them in their everyday practice before, during, and after such events.

Participants described 61 unique benefits to improved resilience to disruption. In Table 1, sub-categories are labelled with the number of unique mentions by participants (in italics, $n=18$ ) and codes are labelled with proportion from the total unique benefits (not italics, $\mathrm{x} / 61$ ). The most frequently mentioned benefits to developing resilience to 
disruption were academic-centric, with academics ...

- being more organised, simplifying their everyday L\&T, and working on other things aside from teaching,

- focusing on learning outcomes, rather than course logistics,

- feeling in control and emotionally prepared for a disruption,

- better supporting their colleagues, learners, and families during a disruption,

- knowing what to expect and things to consider during a disruption,

- having the ability to pass their course on to others in the event of an illness, and

- being encouraged to try new L\&T strategies.

Most benefits focus on 'during the event', followed by 'before the event'. Academic developers and leaders might use this 'dual-benefit' frame (i.e., preparing for disruption will benefit you both now, and in the event of a crisis) to motivate and support individuals to develop resilience over the long-term and with shorter-term disruptions (e.g., going on sabbatical, illnesses).

We also differentiated benefits by key impacted groups (academics, learners and institution) with the most frequently mentioned concerned with academics' competency and emotional state, followed by benefits to L\&T, and to the institution. With the dominant themes pointing to a personal and professional development aspect, building resilience can be directly beneficial to the individual, as well as the institution, and can be communicated this way. Participants also report that building resilience could reduce the emotional impact of disruptive events giving academics more control over what is happening, allowing them to support their learners, colleagues, and families. Perhaps through resilience-building efforts academics might better prepare themselves, emotionally and cognitively, and subsequently reduce the impact of potential events. This is promising, as Kemp et al. [27] report that people with lower levels of emotional stability were more affected by the earthquakes in Canterbury.

On the other hand, participants did not focus on the benefits to the university nor to students. This tells us that the academic's perception of resilience-building described here would also benefit from student engagement. Beaven et al. [28] report that students want to be a part of the solutions rather than 'dictated to' in times of crisis.

There were no significant differences in how the two groups (SG and NSG) described benefits. Participants new to the idea of improving educational resilience noted the same number and types of benefits as those who had spent two years working on the project. Also, academics across the range of teaching experience identified the same number and types of benefits. None of the SG or NSG participants were opposed to, uninterested in, or dismissive of resilience-building. Promisingly, this similarity indicates that benefits to increasing resilience are apparent to those without previous exposure to such thinking. It also signifies that the characterisations developed with the SG above are relevant to those new to the concept of resilience and will be a helpful framework to inform staff.

In conjunction with the characterisation of resilience for academics and institutions, the benefits listed in Table 1 can have two obvious impacts: to communicate to academics why they should undertake resilience-building initiatives, and to convince senior leaders of the need to invest resources in such initiatives.

\subsubsection{Barriers to resilience}

The number of benefits identified by each participant underlines the ease with which resilience concepts can be communicated. However, barriers exist to building resilience. Understanding these barriers can influence the planning and implementation of effective resilience initiatives. The focus in this section is on barriers facing academics while institutional barriers are explored in section 3.2.4.

The 18 participants described 56 perceived barriers to resiliencebuilding across the different levels of the institution (Table 2a-d).
Table 2

Barriers to the improvement of resilience.

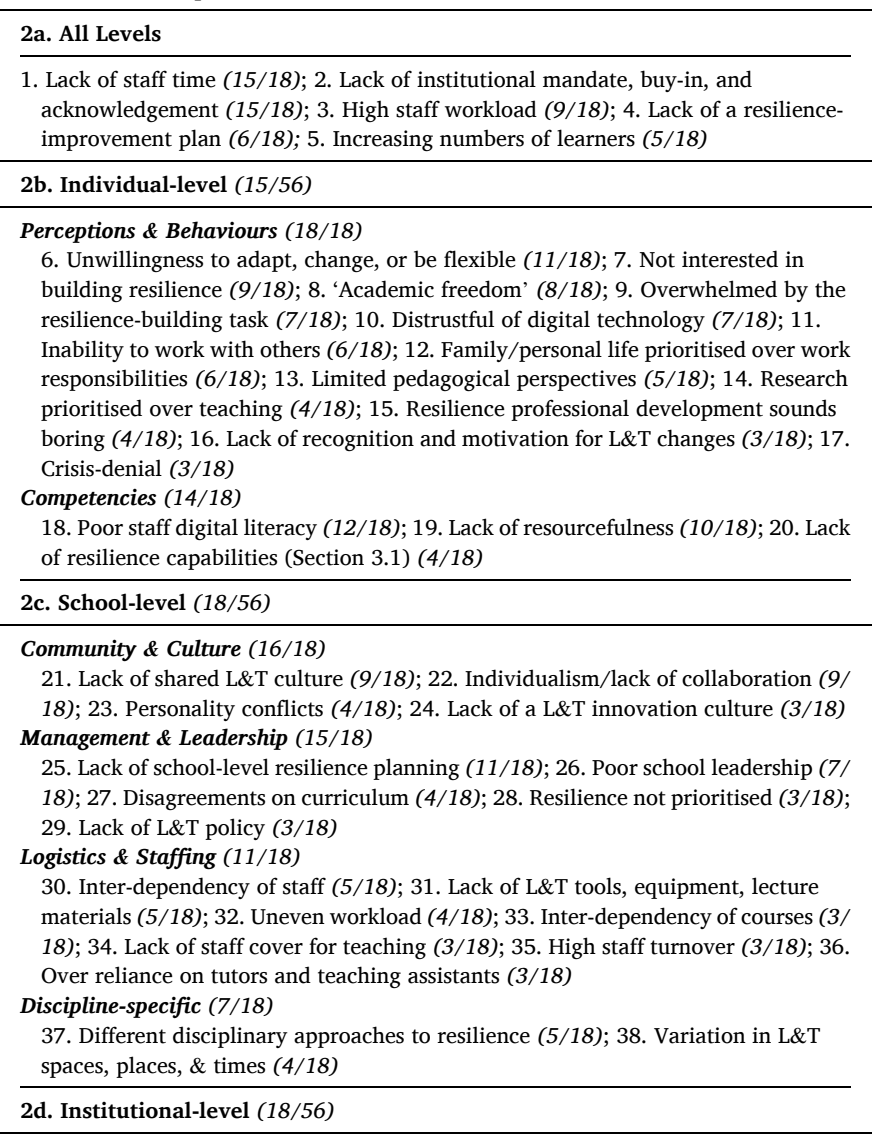

2d. Institutional-level (18/56)

\section{Management \& Leadership (16/18)}

39. Poor institutional leadership (6/18); 40. Lack of longevity in resilience vision and efforts $(6 / 18)$; 41 . Resilience as a standalone initiative; not embedded $(5 / 18)$; 42. Bureaucracy $(3 / 18)$

Infrastructure (14/18)

43. Limited digital systems, structures and processes (12/18); 44. Limited physical systems, structures and processes (9/18); 45. Face-to-face/campus-based culture (5/18)

Support \& Resources (12/18)

46. Lack of rewards to encourage resilience initiatives (10/18); 47. Lack of staff expertise, resources and training $(8 / 18) ; 48$. Lack of funding and material resources $(6 / 18)$

Learners (11/18)

49. Lack of pastoral care model for learners $(8 / 18) ; 50$. Learners are not digitally literate (5/18); 51. Learners have diverse needs (4/18); 52. Learners are expected to be ready-to-learn, without support (4/18); 53. Learners need to be resilient, too ( $3 /$ 18)

Community (10/18)

54. Lack of cohesive and nurturing institutional community (10/18)

Communication (9/18)

55. Ineffective communication between senior leaders and community (7/18); 56 . Ineffective communication between learners and staff $(7 / 18)$

Responses and categories in Table 2 are organised by group and level, with codes listed in order of mention-frequency. Again, no significant differences were reported in barriers by the two participant groups (SG and NSG) or participants with varying levels of teaching experience. These findings represent strongly consistent views.

The most frequently mentioned barriers were:

- Lack of staff time,

- Lack of institutional mandate, buy-in and acknowledgement,

- Poor staff and learner digital literacy,

- Existing digital systems are limited (i.e., poorly performing and lack resilience),

- Academics' unwillingness to change, adapt, and be flexible, 
- Lack of a school-level plan for improving resilience and responding to disruption,

- Lack of cohesive and nurturing institutional community,

- Lack of incentives to encourage resilience initiatives, and

- Academics lack of resourcefulness in finding solutions during disasters.

The most common barrier mentioned is supported by research indicating that academics report feeling overworked with fewer resources [29] and sustaining high workloads. Therefore, academics will require ongoing support and incentives to ensure resilience-building initiatives are undertaken or maintained.

Post-earthquake research [30] indicates that lack of digital literacy among staff, as identified in Table 2 \#18, hinders institutional efforts to respond during and after disruption. Notably, the adoption of digital learning relies on the integration of new and existing tools, staff, and protocols [31] so to develop resilience, ongoing efforts are needed. Also, some teachers moving to flexible or distance learning strategies may express fears about losing ownership over their educational materials (Table 2 \#8: 'Academic freedom'; \#10: 'Distrustful of digital technology') and a potential lack of 'real' contact with students [22].

At the individual-level, several barriers are likely to be difficult to change (e.g. Table 2 \#6 'Unwillingness to adapt, change, or be flexible', \#11 'Inability to work with others' and \#13 'Limited pedagogical perspectives') and could be considered 'innate traits'.

Academics prioritising family and personal life over work responsibilities (Table $2 \# 12$ ) is a barrier that is simultaneously beneficial to their wellbeing and detrimental to staffing during and after a major disruption. University of Canterbury staff experienced overwhelming challenges during the earthquake crisis, particularly those with young children and dependents [6,49]. As illustrated with the COVID-19 pandemic, institutions will need a flexible approach in the immediate wake of a disaster which facilitates academics to care for themselves and their dependents, to be mindful of the gender inequity of care (e.g. Ref. [32]) and a potential greater impact on disabled staff. These workplace protections are best negotiated prior to a major disruption by specifically including all staff contributions and considerations.

It is important to note that this research took place far in advance of the global COVID-19 pandemic. Globally, universities are responding to the pandemic in a multitude of ways. Many academics and institutions have rapidly moved their teaching online and are delivering courses remotely. This rapid change has been termed "emergency remote teaching" and has been differentiated from online learning [33]. Staff are forced to develop and deliver online courses without the standard university support for such endeavours. The barriers identified here are likely to have impacted staff and may continue to do so in future even if courses have moved online. The current rapid move is unlikely to focus on resources that are sustainable in the longer term as such swiftly developed course resources may not be reusable. Further, staff and students may have negative experiences of online L\&T which discourage their continued online or blended delivery.

Interestingly, discipline-based barriers to resilience identified in our research were much less reported than initially anticipated by the researchers. This result reflects Krause's [34] contention that when it comes to L\&T, there may be less of a "hard line" between disciplines than for research.

\subsubsection{Incentives to building resilience}

We also asked participants to identify potential incentives to reduce barriers and enhance resilience across the institution. Table 3 provides readers with 28 strategies that an institution can use to promote and engage staff in resilience-building. Many have cost or time implications, but often address multiple barriers. The number of barriers addressed by each incentive are also listed in the right-hand column of Table 3.

The top three incentives were:
Table 3

Incentives to the improvement of resilience.

\begin{tabular}{|c|c|c|}
\hline A. & Resources \& support (18/18) & $\begin{array}{l}\text { Number of barriers addressed } \\
\ldots \text { (Supplementary Information) }\end{array}$ \\
\hline A1. & $\begin{array}{l}\text { Provide one-on-one staff academic } \\
\text { development support (e.g., to test } \\
\text { resilience initiatives, new products and } \\
\text { procedures, and build digital literacy), } \\
(11 / 18)\end{array}$ & 11 \\
\hline A2. & $\begin{array}{l}\text { Provide resources (i.e., material \& } \\
\text { financial) to support resilience initiatives } \\
(6 / 18)\end{array}$ & 6 \\
\hline A3. & $\begin{array}{l}\text { Make the resilience-building process } \\
\text { accessible, transparent and explicit }(6 / 18)\end{array}$ & 9 \\
\hline A4. & Practice crisis scenarios $(5 / 18)$ & 16 \\
\hline A5. & $\begin{array}{l}\text { Share successful resilience case studies and } \\
\text { 'champions' from our institution and other } \\
\text { disaster experiences }(5 / 18)\end{array}$ & 13 \\
\hline A6. & $\begin{array}{l}\text { Get tutors and graduate students to run } \\
\text { resilience projects and share the workload } \\
(4 / 18)\end{array}$ & 6 \\
\hline A7. & $\begin{array}{l}\text { Provide a resilience-building 'template' for } \\
\text { staff to follow }(1 / 18)\end{array}$ & 6 \\
\hline A8. & $\begin{array}{l}\text { Increase the institution's digital resources } \\
(1 / 18)\end{array}$ & 5 \\
\hline A9. & $\begin{array}{l}\text { Provide resilience information on the } \\
\text { internal institutional website }(1 / 18)\end{array}$ & 7 \\
\hline B. & Acknowledgement from senior seadershi & $(13 / 18)$ \\
\hline B1. & $\begin{array}{l}\text { University leaders demonstrate support } \\
\text { and endorsement for resilience initiatives } \\
(9 / 18)\end{array}$ & 9 \\
\hline B2. & Have a school-level resilience plan $(5 / 18)$ & 12 \\
\hline B3. & Get buy-in from the Head of School (3/18) & 11 \\
\hline B4. & $\begin{array}{l}\text { Have an institutional-level resilience plan } \\
(3 / 18)\end{array}$ & 6 \\
\hline B5. & $\begin{array}{l}\text { Have an annual 'resilience to disruption' } \\
\text { day at the University }(3 / 18)\end{array}$ & 14 \\
\hline B6. & $\begin{array}{l}\text { Emphasize the major losses that the } \\
\text { University would incur }(1 / 18)\end{array}$ & 13 \\
\hline C. & Extrinsic motivators $(11 / 18)$ & \\
\hline $\mathrm{C} 1$. & $\begin{array}{l}\text { Buy-out: Time explicitly set aside to focus } \\
\text { on resilience initiatives }(11 / 18)\end{array}$ & 15 \\
\hline $\mathrm{C} 2$. & $\begin{array}{l}\text { Acknowledge the importance of resilience } \\
\text { explicitly in hiring, promotions, } \\
\text { performance review and KPI's (10/18) }\end{array}$ & 12 \\
\hline C3. & $\begin{array}{l}\text { Acknowledgement and recognition of } \\
\text { excellence in resilience through awards } \\
\text { and cash bonuses }(6 / 18)\end{array}$ & 6 \\
\hline C4. & $\begin{array}{l}\text { Provide funding for staff to take up } \\
\text { resilience initiatives }(3 / 18)\end{array}$ & 10 \\
\hline C5. & Reduce high teaching loads $(1 / 18)$ & 8 \\
\hline C6. & $\begin{array}{l}\text { Encourage resilience-building as a research } \\
\text { opportunity }(1 / 18)\end{array}$ & 8 \\
\hline D. & Community-building (8/18) & \\
\hline D1. & $\begin{array}{l}\text { Communicate about resilience within the } \\
\text { institution and the wider academic } \\
\text { community (4/18) }\end{array}$ & 11 \\
\hline D2. & $\begin{array}{l}\text { Cultivate a stronger sense of community } \\
\text { within and across the schools }(4 / 18)\end{array}$ & 11 \\
\hline D3. & $\begin{array}{l}\text { Share L\&T practice within schools to } \\
\text { encourage capacity building }(3 / 18)\end{array}$ & 17 \\
\hline D4. & $\begin{array}{l}\text { 'Grass roots': Empower academics to be a } \\
\text { part of the resilience-building process (1/ } \\
\text { 18) }\end{array}$ & 13 \\
\hline E. & \multicolumn{2}{|c|}{ Incorporate and acknowledge resilience in day-to-day procedures $(6 / 18)$} \\
\hline E1. & $\begin{array}{l}\text { Emphasize and embed resilience within } \\
\text { institutional L\&T, course re-development } \\
\text { and everyday teaching }(5 / 18)\end{array}$ & 12 \\
\hline E2. & $\begin{array}{l}\text { Embed resilience within health and safety } \\
\text { procedures and emergency protocols ( } 2 / \\
\text { 18) }\end{array}$ & 2 \\
\hline E3. & $\begin{array}{l}\text { Emphasize the benefits of resilience in } \\
\text { other types of absences (e.g., sabbatical) } \\
(2 / 18)\end{array}$ & 4 \\
\hline
\end{tabular}


- providing one-on-one staff academic/educational development support,

- providing buy-out for academics to explicitly focus on these initiatives, and

- university leadership demonstrating support and endorsement for resilience initiatives

\subsubsection{Reconciling barriers and incentives}

Barriers to resilience-building and the incentives to overcome these barriers are intrinsically linked. The key themes identified, how each barrier can be addressed, and a detailed description and consideration of how key incentives can be enacted are described in this section.

Lack of community was a prominent barrier at the school- and institutional-level identified by most participants (Table 2). Communities of practice [35] are known to support changes in L\&T practice [36], enhance innovative and flexible L\&T learning approaches [22], and are critical for supporting learners in a crisis [30]. Additionally, research has shown that in times of crisis, community support (or the perception thereof) is strongly related to 'people feeling normal again' $[7,37]$. We recommend that universities incorporate community-building efforts into their resilience plan, such as shared activities in L\&T innovation [38].

Five teaching-dominant participants in our research explicitly linked the lack of cooperative institutional-level community and culture at our university to the lack of recognition and importance of L\&T. Similar to other academic institutions worldwide [29], L\&T was not perceived as a key criterion for promotion. Also, many academics are overworked with less resources [29] and L\&T and research are seen, by some, as adversaries [39]. To support resilience initiatives, acknowledgement, endorsement, and engagement from senior leaders is needed (Tables 2c, 2d, 3b). Senior leaders can support resilience efforts in many ways, namely through reward and recognition schemes for L\&T community initiatives (supported by results here and also in Ref. [34]). For example, our university redesigned its promotion criteria to more explicitly acknowledge L\&T in 2018.

Notably, while it may be appealing for leaders to use the results of this work to enact 'top-down' changes, a divide often exists between managerial approaches to higher education and academics' desire for autonomy [40,41] within supportive communities of practice and scholarship. Mandating action on resilience may not be the most effective and supportive route for academic staff. We suggest a blended approach (top-down and bottom-up) leading to a series of interconnected efforts across the levels of the organisation, including learners, and effecting positive resilience improvement [20,21]. At our university, school leadership changes every three years, potentially lead to loss of continuity in resilience initiatives. Knowledge transfer at the institutional level is therefore critical to ensure continuity of long-term resilience initiatives.

The bottom up approach detailed here does not draw on risk or resilience quantification where the extent of the greatest risk or lowest resilience is known across different areas of the organisation [26]. Our process is one of resilience building across the L\&T curriculum, but this process also needs to fit with organisation-wide procedures which are more akin to other large-scale organisations, such as business continuity plans. Within a resilience quantification framework, targeting particular academic disciplines may make the most sense (e.g., those with costly teaching laboratories). If such an approach is followed, the incentives and barriers identified here may be helpful in working with academic staff in targeting high risk areas to purposefully increase these strategic areas of resilience.

Resources and support are the backbone of L\&T professional academic development. Staff and learners need to be digitally capable, and infrastructure (virtual and physical) is needed to support flexible learning. Lacking both of these elements poses a significant barrier to resilience. As learning management system technology evolves or courses move from emergency remote teaching to a purposefully designed online model, staff and learners will require continual training. Not all staff will want to engage in flexible learning with the perceived loss of ownership over their courses a noteworthy fear among academics [22]. Resilient higher education institutions should prioritise support services integral to long-term, sustainable changes [42]. Professional development in resilience can be facilitated through workshops or one-on-one support with educational technologists and academic developers (Table $3 \mathrm{~A} 1$ ), recognising that individual support is less possible in the immediate aftermath of a disaster event due to high demand. We also note, though, that professional development may not be appropriate for all perceptions and behaviours as those behaviours may be linked to internal values and resistant to change (Table 2).

Implementing L\&T in some disciplines requires more physical infrastructure than wholly online, flexible, or distance learning approaches can provide. For example, conventional geoscience education relies on face-to-face hands-on laboratory lessons. This infrastructure could be damaged during major disruptions, or access could become limited. When discussed, participants perceived this possibility as an opportunity to develop alternative settings/modes of L\&T rather than an insurmountable challenge. For example, a blended learning approach can provide some physical access to materials and equipment, supported with online learning opportunities. We recommend using the online learning environment to foster unique approaches, to increase learner engagement and maintain a 'minimum online presence' (i.e., contact information, unit outlines, weekly agenda, and communication channels), which learners can use to communicate with peers and staff. We see this meaningful online environment as the first 'goal post' towards resilience, even if the online space is simply an alternative for face-toface activities (e.g., delivery of lectures, readings and assessments).

Furthermore, we assessed which incentives might be the most potent in reducing barriers to resilience. The authors matched and summed the number of barriers addressed by each of these incentives (Table 3, righthand column; Supplementary Information). Some barriers could be more 'easily' reduced or mitigated, others much less so, and 7 barriers had no incentive provided by the participants (Table $3 \# 5,6,11,30,33$, 35 , and 36). However, most of the incentives addressed more than ten barriers, with three "high impact" incentives of:

- Sharing L\&T practice within schools to encourage capacity-building,

- Practicing crisis scenarios, and

- Buy-out: providing time from other duties to focus on resiliencebuilding.

These three incentives are key opportunities for change. For example, when practitioners participate in crisis scenario-based exercises, they identify priorities, test out new ideas, improve communication flow, and develop group rapport and trust [43-45] all of which help to foster resilience. Participants also talked extensively about the incentive of buy-out (i.e., using funding to pay for teaching or administrative support) providing academics much needed time to test resilience initiatives. In New Zealand, buy-out is commonly used to focus on research. We propose that 'resilient teaching buy-out' could be a powerful experience, with far-reaching impacts. We suggest institutions trial buy-out schemes to give staff with the greatest vulnerabilities to disruption (i.e., highest student numbers, most dependent on physical infrastructure, caring responsibilities, etc.) or early adopters (i.e., engaged staff likely to implement initiatives and inspire others around them to build resilience) the time to creatively identify, plan, and implement unique resilience-building solutions.

At a minimum, we recommend that a business continuity plan is cocreated by academics, senior leaders, and business continuity experts. To promote longevity and sustainability, planning needs to take a longterm view [4] and leaders need to buy-in and promote resilience initiatives. For those seeking guidance in campus responses to disasters, there is a range of existing research which discusses universities' preparedness and overall response to crisis and organisation-level 
communication management and planning [3,6,28,46-48]. A prepared and responsive university would help to ensure that the institution continues to function as a business, that learners continue their studies, and therefore staff and student wellbeing can be prioritised $[11,13]$.

\section{Conclusions}

This study explored academics' perceptions of resilience to disruption and documented the perceived benefits, barriers, and incentives of resilience-building. Our approach contributes to the literature through its multidisciplinary lens by including participants across a spectrum of disciplines (e.g., including psychology, geography, biology, chemistry, and science history), with different teaching commitments, and by including both academic and professional staff. The collation of responses across different academic disciplines and the similarity of those responses across our participants for L\&T demonstrates the wider applicability of our results. Our focus on academics enhances the understanding of impacts on and incentives for resilience on individual practice. However, our focus on individual practice and perceptions does not replace the need for an organisation-level assessment. Further, higher education is infrequently explored and investigated within the resilience literature. We applied a pragmatic approach and mixed methods methodology within a university in New Zealand, though we propose that the results can be used to build resilience in many other higher education contexts.

The key findings and discussion are grouped into the three distinct levels of the university (individual, school, and institution), so that resilience-building strategies are readily facilitated by individuals, schools, and institutional senior leaders. Tables 1-3 are presented in a way that allows direct application to practice, reducing the burden for individuals, and streamlining the call-to-action. The benefits of continued resilience to disruption for new and existing staff outside of an immediate threat need to be understood to ensure resiliency gains are built upon, rather than lost, in a return to business as usual. Awareness of the continued benefits to resilient teaching may encourage the continued engagement of academics in rethinking and reprioritising their course delivery and teaching practices to ensure continued resilience.

Our research highlights the importance of support, community, and leadership at universities. We also present dual-benefits of implementing flexible learning strategies, which can support meaningful L\&T even if face-to-face interactions cannot take place after a disruption. This enables the framing of resilience initiatives as meaningful, regardless of whether an event happens or not. However, if a disaster does occur, we should not dismiss face-to-face interactions where possible (e.g., earthquake rather than pandemic scenario), because stronger community connections are important for 'feeling normal again'.

Resilience to disruption will be experienced differently across educational and socio-political contexts, where benefits, barriers, and incentives may be of greater/lesser importance. Every university, therefore, needs to build a customised plan taking into consideration its unique vulnerabilities and areas for improvement. Such quantification methods have been discussed elsewhere. Universities comprise complex, tiered relationships between the levels (individuals, schools, and leaders) that are negotiated through communities of practice with unique decision-making and power distributions. It may be appealing for senior leaders to use the results of this work to enact 'top-down' changes in response to these, commonly, institution-based frameworks, but we recommend a blended strategy (top-down and bottom-up) that supports academics' autonomy and diversity in L\&T.

In most contexts, we cannot change that disasters happen but we can change how vulnerable our universities are to these events and we can reduce the impacts to our people and property. By documenting barriers and highlighting benefits and incentives, we hope academics, senior leadership, and professional staff can enact changes across all levels of their institution, ultimately leading to reduced risk from disaster and long-term disruptions.

We hope that this research will benefit those currently working to continue L\&T despite the overwhelming challenges presented by the COVID-19 pandemic and other disasters.

\section{Funding details}

This work was supported by funding from Victoria University of Wellington, New Zealand; under a research grant (\#205830; "Exploring Educational Flexibility \& Resilience in Learning and Teaching”).

\section{Declaration of competing interest}

There is no financial interest or benefit that has arisen from the direct applications of this research. There are no competing interests to declare. The researchers declare there are no personal relationships with people or organisations that could inappropriately influence this research.

\section{Appendix A. Supplementary data}

Supplementary data to this article can be found online at https://doi. org/10.1016/j.ijdrr.2020.101691.

\section{References}

[1] M.K. Van Aalst, The impacts of climate change on the risk of natural disasters, Disasters 30 (2006) 5-18, https://doi.org/10.1111/j.1467-9523.2006.00303.x.

[2] C. SchWeber, Determined to learn: accessing education despite life-threatening disasters, J. Async. Learn. Network 12 (2008) 37-43. Retrieved from: https://eric. ed.gov/?id=EJ837468.

[3] E.P. Fillmore, M. Ramirez, L. Roth, M. Robertson, C.G. Atchison, C. Peek-Asa, After the waters receded: a qualitative study of university official's disaster experiences during the Great Iowa Flood of 2008, J. Community Health 36 (2011) 307-315, https://doi.org/10.1007/s10900-010-9312-z.

[4] N. Kapucu, S. Khosa, Disaster resiliency and culture of preparedness for university and college campuses, Adm. Soc. 45 (2013) 3-37, https://doi.org/10.1177/ 0095399712471626.

[5] I. Linkov, B.D. Trump, The Science and Practice of Resilience, Springer International Publishing, 2019.

[6] E. Seville, C. Hawker, J. Lyttle, Shaken but Not Stirred. A University's Resilience in the Face of Adversity, University of Canterbury, Christchurch, New Zealand, 2011.

[7] G.A. Bonanno, C.R. Brewin, K. Kaniasty, A.M.L. Greca, Weighing the costs of disaster: consequences, risks, and resilience in individuals, families, and communities, Psychol. Sci. Publ. Interest 11 (2010) 1-49, https://doi.org/ 10.1177/1529100610387086.

[8] A. Vance, D. Pendergast, S. Garvis, Teaching resilience: a narrative inquiry into the importance of teacher resilience, Pastor. Care Educ. 33 (2015) 195-204, https:// doi.org/10.1080/02643944.2015.1074265.

[9] J.A. Downey, Recommendations for fostering educational resilience in the classroom, Prev. Sch. Fail.: Alter. Educ. Child. Youth 53 (2008) 56-64, https://doi. org/10.3200/PSFL.53.1.56-64.

[10] C. Knight, A resilience framework: perspectives for educators, Health Educ. 107 (6) (2007) 543-555.

[11] R. Bates, Institutional continuity and distance learning: a symbiotic relationship, Online J. Dist. Learn. Adm. 16 (2013) 7p. Retrieved from: https://eric.ed.gov/? $\mathrm{id}=\mathrm{EJ} 1020110$.

[12] M. Houston, The Experiences of Faculty at Academic Institutions Preparing Themselves for Academic Continuity after a Disaster in Florida in the Last Decade: A Phenomenological Study, Doctoral dissertation, 2016. Retrieved from ProQuest: 10106247.

[13] C. SchWeber, Survival lessons: academic continuity, business continuity, and technology, in: Facilitating Learning in the 21st Century: Leading through Technology, Diversity and Authenticity, Springer, Dordrecht, 2013, pp. 151-163.

[14] O. Ekmekci, J. Bergstrand, Agility in higher education: planning for business continuity in the face of an H1N1 pandemic, Quart. J. S.A.M. Adv. Manag. J. 75 (4) (2010) 20-30, 2.

[15] M. Feilzer, Doing mixed methods research pragmatically: implications for the rediscovery of pragmatism as a research paradigm, J. Mix. Methods Res. 4 (2010) 6-16, https://doi.org/10.1177/1558689809349691.

[16] D. Johnston, J. Becker, J. McClure, D. Paton, S. McBride, K. Wright, M. Hughes, Community understanding of, and preparedness for, earthquake and tsunami risk in Wellington, New Zealand, in: Cities at Risk, Springer, Dordrecht, 2013, pp. 131-148.

[17] S.H. Potter, J.S. Becker, D.M. Johnston, K.P. Rossiter, An overview of the impacts of the 2010-2011 Canterbury earthquakes, Int. J. Disas. Risk Red. 14 (2015) 6-14, https://doi.org/10.1016/j.ijdrr.2015.01.014. 
[18] N. Healey, The 2010 and 2011 Canterbury earthquakes and organisational learning at the University of Canterbury: does practice make perfect? J. Manag. Organ. 17 (2011) 850-856, https://doi.org/10.1017/S1833367200001218.

[19] L. Cohen, L. Manion, K. Morrison, Research Methods in Education, sixth ed., Routledge, New York, NY, 2007.

[20] S.T. Hannah, P.B. Lester, A multilevel approach to building and leading learning organizations, Leader. Q. 20 (2009) 34-48, https://doi.org/10.1016/j. leaqua.2008.11.003.

[21] T. Roxå, K. Mårtensson, How effects from teacher-training of academic teachers propagate into the meso level and beyond, in: Teacher Development in Higher Education: Existing Programs, Program Impact, and Future Trends, Routledge, 2012, pp. 213-233.

[22] E. Errington, The impact of teacher beliefs on flexible learning innovation: some practices and possibilities for academic developers, Innovat. Educ. Teach. Int. 41 (2004) 39-47, https://doi.org/10.1080/1470329032000172702.

[23] I. Linkov, C. Fox-Lent, L. Read, C.R. Allen, J.C. Arnott, E. Bellini, J. Coaffee, M. V. Florin, K. Hatfield, I. Hyde, W. Hynes, Tiered approach to resilience assessment, Risk Anal. 38 (9) (2018) 1772-1780.

[24] A.H. Kwok, E.E. Doyle, J. Becker, D. Johnston, D. Paton, What is 'social resilience'? Perspectives of disaster researchers, emergency management practitioners, and policymakers in New Zealand, Int. J. Disas. Risk Red. 19 (2016) 197-211.

[25] National Research Council, Facing Hazards and Disasters: Understanding Human Dimensions, The National Academies Press, Washington, DC, 2006, https://doi. org/10.17226/11671.

[26] M.D. Wood, E.M. Wells, G. Rice, I. Linkov, Quantifying and mapping resilience within large organizations, Omega 87 (2019) 117-126.

[27] S. Kemp, W.S. Helton, J.J. Richardson, N.M. Blampied, M. Grimshaw, Sleeplessness, stress, cognitive disruption and academic performance following the September 4, 2010, Christchurch earthquake, Australas. J. Disaster Trauma Stud. 2 (2011) 11-18. Retrieved from: https://www.massey.ac.nz/ trauma/issues/ 2011-2/contents.htm.

[28] S. Beaven, L. Johnston, T.M. Wilson, E. Brogt, J. Blythe, C. Reugg, J. Lyttle, Risk and resilience factors reported by a New Zealand tertiary student population after the 4th September 2010 Darfield Earthquake, Int. J. Mass Emergencies Disasters 32 (2014) 375-404. Retrieved from: http://www.ijmed.org/articles/661/.

[29] D. Adams, Examining the fabric of academic life: an analysis of three decades of research on the perceptions of Australian academics about their roles, High Educ. 36 (1998) 421-435, https://doi.org/10.1023/A:1003423628962.

[30] J. Mackey, D. Breeze, P. Buckley, N. Dabner, F. Gilmore, Riding the seismic waves: re-blending teacher education in response to changing demands, in: Paper Presented at Ascilite 2011, Hobart Tasmania Australia, 2011.

[31] F. Blin, M. Munro, Why hasn't technology disrupted academics' teaching practices? Understanding resistance to change through the lens of activity theory, Comput. Educ. 50 (2) (2008) 475-490, https://doi.org/10.1016/j. compedu.2007.09.017.

[32] N. Folbre, The care penalty and gender inequality, in: S. Averett, L. Arys, S. Hoffman (Eds.), The Oxford Handbook of Women and Economy, 2017, pp. 1-28.

[33] C. Hodges, S. Moore, B. Lockee, T. Trust, A. Bond, The Difference between Emergency Remote Teaching and Online Learning, EDUCAUSE Review, 2020. htt ps://er.educause.edu/articles/2020/3/the-difference-between-emergency-remote -teachingand-online-learning.

[34] K.L.D. Krause, Challenging perspectives on learning and teaching in the disciplines: the academic voice, Stud. High Educ. 39 (2014) 2-19, https://doi.org/10.1080/ 03075079.2012.690730.

[35] E. Wenger, Communities of Practice: Learning, Meaning, and Identity, Cambridge university press, London, 1999.

[36] V. Vescio, D. Ross, A. Adams, A review of research on the impact of professional learning communities on teaching practice and student learning, Teach. Teach. Educ. 24 (2008) 80-91, https://doi.org/10.1016/j.tate.2007.01.004.

[37] D.A. Gill, Secondary trauma or secondary disaster? Insights from hurricane katrina, Socio. Spectr. 27 (2007) 613-632, https://doi.org/10.1080/02732170701574941.

[38] S. Cherrington, A. Macaskill, R. Salmon, S.M. Boniface, S. Shep, J. Flutey, Developing a pan-university professional learning community, Int. J. Acad. Dev. 23 (2017) 298-311, https://doi.org/10.1080/1360144X.2017.1399271.

[39] P. Roberts, Higher education curriculum orientations and the implications for institutional curriculum change, Teach. High. Educ. 20 (2015) 542-555, https:// doi.org/10.1080/13562517.2015.1036731.

[40] P. Ramsden, Learning to Lead in Higher Education, Taylor \& Francis, 1998.

[41] R. Winter, Academic manager or managed academic? Academic identity schisms in higher education, J. High Educ. Pol. Manag. 31 (2009) 121-131, https://doi.org/ $10.1080 / 13600800902825835$.

[42] S. Toohey, Designing Courses for Higher Education, Open University Press, Philadelphia, 1999.

[43] J. Dohaney, E. Brogt, B. Kennedy, T.M. Wilson, J.M. Lindsay, Training in crisis communication and volcanic eruption forecasting: design and evaluation of an authentic role-play simulation, J. Appl. Volcanol. 4 (12) (2015), https://doi.org/ 10.1186/s13617-015-0030-1.

[44] J. Dohaney, E. Brogt, T.M. Wilson, B. Kennedy, Using role-play to improve students' confidence and perceptions of communication in a simulated volcanic crisis, in: C.J. Fearnley, D.K. Bird, K. Haynes, W.J. McGuire, G. Jolly (Eds.), Observing the Volcano World, Springer, Barcelona, 2017, pp. 691-714.

[45] E. Seville, D. Brunsdon, A. Dantas, J. Le Masurier, S. Wilkinson, J. Vargo, Organisational resilience: researching the reality of New Zealand organisations, J. Bus. Continuity Emerg. Plan. 2 (2008) 258-266. Retrieved from: http://europe pmc.org/abstract/MED/21339112.

[46] N. Dabner, 'Breaking Ground' in the use of social media: a case study of a university earthquake response to inform educational design with Facebook, Internet High Educ. 15 (2012) 69-78, https://doi.org/10.1016/j. iheduc. 2011.06.001.

[47] L. Palen, Online social media in crisis events, Educ. Q. 31 (2008) 76-78. Retrieved from: https://www.learntechlib.org/p/101343/.

[48] A. Tanner, B. Doberstein, Emergency preparedness amongst university students, Int. J. Disas. Risk Red. 13 (2015) 409-413, https://doi.org/10.1016/j. ijdrr.2015.08.007.

[49] Seaton, L., Seaton, P., Yarwood, J., \& Ryan, M. (2012). Preparedness for Sudden Change: Lessons from managing large-scale disruption within a Bachelor of Nursing community: Final Report. Ako Aotearoa - National Centre for Tertiary Education. Retrieved from https://akoaotearoa.ac.nz/download/ng/file/group-7 /preparedness-for-suddenchange-project-report.pdf. 